\title{
Addressing threats like Covid: why we will tend to over-react and how we can do better
}

\author{
Mark Pingle ${ }^{1}$ (])
}

Received: 3 July 2020 / Accepted: 6 February 2022 / Published online: 8 March 2022

(C) The Author(s), under exclusive licence to Springer-Verlag GmbH Germany, part of Springer Nature 2022

\begin{abstract}
A number of behavioral economic insights suggest we will tend to overreact, individually and collectively, to a new, serious, but low probability health threat, like Covid 19. To respond more effectively to such threats, we should recognize why we will tend to overreact and prepare in advance not to do so. We also should recognize the usefulness in giving lower level governments, non-profits, and less formal communities some ability to respond, rather than presuming we should address a significant threat like Covid using the highest level of government.
\end{abstract}

Keywords Covid · Loss aversion · Status quo bias · Certainty effect · Ambiguity · Emotion

\section{Introduction}

The possibility of becoming infected with the Sars-Cov2 virus and experiencing a Covid19 disease is a private good problem and a public good problem. Privately, you have reason to take action to mitigate the new threat to your health. Social distancing, mask wearing, sanitizing and shutting down your business are costly actions, but you might choose to engage in them to some degree because reducing your probability of being infected may provide net benefits. However, such private actions also generate positive externalities because they reduce the probability you will infect others, or we can say that acting to reduce virus spread is a contribution to a public good. By living less freely, you reduce the possibility that you emit a negative externality that will occur if you contract and spread the virus.

Desires for justice and welfare motivate government intervention. Additional government restrictions and spending will tend to impose costs on you and me, but these additional costs are justified if they sufficiently reduce the negative externalities or sufficiently internalize them. The additional individual benefits you and I

Mark Pingle

pingle@unr.edu

1 University of Nevada, Reno, USA 
receive from the enhanced public good (i.e. the reduced likelihood of infection) will increase our individual welfare if they outweigh the additional costs we experience.

However, as Coase (1960) well expressed, identifying the most effective way to address an externality is not easy. In part, this is because the social costs imposed by negative externalities are reciprocal: "To avoid the harm to B would inflict harm on A (Coase, 1960, p. 2)." Consequently, Coase (1960, p. 2) contends the first question we must answer is a rights question: "Should A be allowed to harm B or should B be allowed to harm A?" Coase's Theorem is that, if we effectively specify rights and transactions costs are zero, then any assignment of rights will lead to the same outcome; so government need not intervene. Of course, transactions costs are normally not zero, so Coase (1960, p. 18) describes the general problem as "choosing the appropriate social arrangement for dealing with the harmful effects." He concludes, "It is all a question of weighing up the gains that would accrue from eliminating these harmful effects against the gains that accrue from allowing them to continue (Coase 1960, p. 26)."

This paper explains why particular behaviors studied behavioral economists and psychologists suggest government policy makers, along with private decision-makers, will tend to over react to any new threat like Covid 19. Over-reaction implies some government policy actions will generate costs greater than the benefits, but also over-reaction will also take the form of higher-level governments discounting the adaptive capabilities of individuals, private sector groups, non-profits, and lower level governments. Of course, this does not imply government should take no action, nor does it imply higher-level governments should assume lower level governments and others will respond sufficiently. The hope offered by this paper is that a more refined understanding of the factors motivating reactions to a very serious but low probability threat like Covid 19 will lead to better choices, individually and collectively.

\section{Behavioral factors influencing the response}

Samuelson and Zeckhauser (1988) present some experiments and theory that identify and explain a "status quo bias." For multiple reasons, the existing situation or choice is a reference point to which people will assign extra value compared to possible alternatives. The introduction of SARS-COV2 posed new potential losses to nearly everyone. The new situation was a deviation from the status quo. Traditional cost-benefit analysis predicts a new threat to health will motivate individual action and a desire for government action, but the status quo bias enhances these motivations. That is, the desire to maintain the status quo is one potential cause of over-reaction.

Loss aversion (Kahneman and Tversky 1979) is a particular status quo bias. Loss aversion indicates people will pay more to reduce their potential losses caused by Covid than they would pay to obtain a gain by reducing some other potential harm by an equivalent amount.

The "endowment effect" of Kahneman et al. (1990) is very much related. At any given time, people possess particular health situations, or endowments. The 
endowment effect indicates people value something more when they already possess it than they would be willing to pay to obtain it. Thus, the endowment effect indicates we will be more willing to pay to maintain our world without Covid than we would be willing to pay to eliminate Covid if we had already been living with it.

Loewenstein (2000) provides evidence that emotional reactions cause our preferences to be emotionally state dependent. The "risks-as-feelings" hypothesis (Loewenstein et al 2001) indicates our hot emotional response to a risky situation will cause us to perceive more risk than cold cognitive evaluation would perceive. The imminence of the risk, a more vivid imagination of the possible consequences, and past personal experiences are factors that tend to bias and magnify risk perceptions. "Media coverage of vivid cases" will magnify our emotion and may transform it into panic (Loewenstein et al 2001, p. 279). The applicability to Covid is apparent.

Loewenstein et al (2001, p. 275) contend that emotion provides an explanation of the "certainty effect" of Allais (1953), a decision bias where irrational value is placed on no chance as opposed to a very small chance, noting "the overweighting of small probabilities is a result of feelings of fear ... in the case of a negative outcome." The probability of serious harm from Sars-Cov2 was zero a short time ago. The Allais paradox predicts we (and the government officials who represent us) will overweight the small probability of harm face from Covid because it was zero not long ago.

The probability of harm from Covid is also ambiguous, meaning we do not know it with precision. How deadly is the virus for someone of a given age and health condition? How much difference does a mask of a certain type make in a particular situation? How much will shutting down a business of a given type reduce the spread of the virus? While we know more now than when the virus first arose, answers to these probability questions are still ambiguous to some degree. Under ambiguity, more optimistic people behave differently because they assign smaller probabilities to negative possible outcomes. When the probability of a loss is small, as it is with Covid, the presence of ambiguity will augment risk aversion for all but the most optimistic of people. ${ }^{1}$ Thus, ambiguity about the probability of harm from Sars-Cov2 will also tend to amplify desires to reduce the spread of the virus.

To summarize, a variety of behavioral forces will tend to bias the standard economic cost-benefit analysis toward over-reacting to Covid. The appearance of any new threat to health and safety should motivate action to reduce the threat. As an individual, you should shift time, money, and other resources toward reducing the new threat until the benefit of reducing the threat further is not worth it because you could better use those resources in another away (e.g. reducing some other threat to your health). However, the Allais paradox indicates you will bias your actions toward addressing the new threat just because it is new. The endowment effect and loss aversion indicate you will bias your actions toward reducing the new threat

\footnotetext{
1 For a simple but general model of ambiguity, see Wuthisatian et al. (2022). Using a modified version of the ambiguity model developed by Gilboa and Schmeidler (1989) and extended by Chateauneuf et al. (2007), Wuthisatian et al. (2022) show that a single model of ambiguity can explain a variety of behaviors that violate the more standard subjective expected utility theory.
} 
compared to reducing status quo existing threats. The risks as feelings hypothesis indicates the emotion generated by the new threat will further bias you toward addressing the Covid threat compared to existing threats. The ambiguity of the new situation will amplify your reaction compared to what it will be when you know more in the future.

Over time, we should expect the bias to disappear. If the threat of Covid 19 does not entirely disappear, a new normal will eventually become the new reference point for any status quo bias. A Covid 19 illness will no longer represent a loss from the norm, but some amount of illness and death from Covid will become the norm. The extra emotion associated with Covid 19 will subside as the culture incorporates deaths and sickness from Covid into its expectations as it has for other long existing causes of deaths and sickness. The ambiguity will decrease as we learn just how much difference age, health condition, vaccines, masks, distancing and other factors make. As the bias disappears, we should observe our over-reaction disappear. We will still devote resources toward any Covid health threat, but will more properly balance the resource allocation relative to alternative uses.

\section{Additional factors influencing government policy makers}

When we weigh one benefit (e.g., reducing disease and death) against another (e.g., maintaining freedoms and livelihoods), we must bring our values, preferences, and priorities into consideration. Parroting Frank Knight, Coase (1960, p. 43) claimed the "problems of welfare economics must ultimately dissolve into a study of aesthetics and morals." Median voter theory and public choice theory provide insights regarding the values and preferences that policy makers will prioritize.

Florio and Colautti (2005) provide evidence that public demands for controlling externalities and public goods grow as the income of the median voter grows. Health and safety products are normal or luxury goods, not inferior goods. Consequently, people will not only buy more privately as their incomes grow, but also they will vote to obtain more from the public sector. That is, we can explain government actions to reduce the spread of the virus, like vaccine mandates, mask mandates, stay at home orders, and business shut down orders, as expressions of median voter preferences. The work of Florio and Colautti indicates we should expect stronger reactions to a new threat like Covid 19 among higher income people. Also, we should expect people who are wealthier than the median voter to view the government actions as too weak and people who are poorer than the median to view the actions as too strong.

Stigler's (1971) theory of regulation posits that special interest groups demand regulations and governments supply them. Peltzman's (1976) theory predicts government will supply smaller groups of varying types with the regulation they demand because the returns to lobbying diminish as the size of the group increases. Carrigan and Coglianese (2015, p. 291) conclude that the "rational regulator [seeks] an outcome that optimizes political support from all groups interested in regulation." These perspectives on regulation predict government actions to confront Sars-Cov2 
will extend beyond the interests of the median voter. In particular, government actions will cater to a variety of special interests.

Sunstein and Zeckhauser (2011) explain why government will tend to overreact to a "fearsome risk," which they define as a low probability risk that generates considerable emotion or anxiety because it involves losing something significant. Consistent with Loewenstein et al (2001), Sunstein and Zeckhauser contend that the presence of fear leads to "probability neglect," which involves mostly ignoring the probability and focus primarily on the bad outcome. They contend this is what leads to an overreaction they call "action bias," and they claim this "bias is especially likely if the relevant actors will be able to obtain credit for responding to the risk" (Sunstein and Zeckhauser 2011, p. 437). President Teddy Roosevelt actually recommended that policy makers have an action bias when he said, "In any moment of decision, the best thing you can do is the right thing, the next best thing is the wrong thing, and the worst thing you can do is nothing."

Using the 2008-2009 financial crisis as context, Higgs (2010) explains why government will not only tend to over-react to a crisis but also why higher levels of government will tend to usurp action opportunities of lower level governments. Higgs (2010, p. 549) notes that private parties typically have a "great incentive" to "meet the existing challenges by means of their own devising," but this is typically ignored and "government decision makers who wield the greatest power at the time assume that central government action ought to be the first resort in a perceived crisis." To gain support for high-level government action, Higgs provides evidence that policy makers often exaggerate the risk, insisting "that the impending dangers are so ominous that unless extraordinary measures are taken immediately a catastrophe may occur" (Higgs 2010, p. 545). Higgs provides evidence to support his claim of over-reach in the response to the financial crisis, including responses to increased special interest lobbying as predicted by the regulatory theory mentioned above. Without knowing about the upcoming Covid crisis, Higgs (2010) also notes that an exceptionally strong response to one crisis, the financial crisis being his focus, would build in expectations that government respond similarly in the future.

Doring and Schnellenback (2011) examine Germany and the U.S. and explain why societies with decentralized government naturally evolve toward having a more centralized government. They contend, "state and local governments do not enjoy the pressures of fiscal competition," so "they are willing to give up autonomy if they can gain security, for example through a far-reaching fiscal equalization scheme, through other grants-in-aid, or through tax sharing" (Doring and Schnellenback 2011, p. 100). The U.S. government has much more ability to borrow than any state, and can finances its deficit spending through Federal Reserve purchases of the debt. To obtain the funds the national government allocates to cooperative states, it is reasonable to think most states will accept the federal government's lead on how to address Covid. Because state and federal governments also distribute monies to local governments and to private businesses and citizens, local governments, businesses and individuals are also motivated to adopt higher-level government directives. 
Table 1 COVID Deaths as of September 11, 2021

\begin{tabular}{|c|c|c|c|c|}
\hline \multirow[t]{2}{*}{ Age group } & \multicolumn{2}{|l|}{ COVID deaths } & \multicolumn{2}{|l|}{ Total deaths } \\
\hline & $\begin{array}{l}\text { Number of } \\
\text { Covid deaths }\end{array}$ & $\begin{array}{l}\text { Percent of Covid } \\
\text { deaths }(\%)\end{array}$ & Number of total deaths & $\begin{array}{l}\text { COVID percent of } \\
\text { total deaths }(\%)\end{array}$ \\
\hline Under 1 year & 105 & 0.02 & 31,744 & 0.33 \\
\hline $1-4$ years & 54 & 0.01 & 5881 & 0.92 \\
\hline 5-14 years & 145 & 0.02 & 9374 & 1.55 \\
\hline $15-24$ years & 1297 & 0.20 & 60,337 & 2.15 \\
\hline $25-34$ years & 5759 & 0.87 & 125,214 & 4.60 \\
\hline $35-44$ years & 14,423 & 2.19 & 180,908 & 7.97 \\
\hline $45-54$ years & 37,451 & 5.69 & 324,502 & 11.54 \\
\hline $55-64$ years & 87,847 & 13.34 & 739,872 & 11.87 \\
\hline $65-74$ years & 147,568 & 22.40 & $1,132,873$ & 13.03 \\
\hline $75-84$ years & 176,763 & 26.83 & $1,353,163$ & 13.06 \\
\hline 85 years and over & 187,342 & 28.44 & $1,624,027$ & 11.54 \\
\hline All Ages & 658,754 & 100.00 & $5,587,895$ & 11.79 \\
\hline $0-17$ years & 439 & 0.07 & 56,092 & 0.78 \\
\hline
\end{tabular}

https://www.cdc.gov/nchs/nvss/vsrr/covid_weekly/index.htm\#SexAndAge Retrieved September 19, 2021

\section{The high cost of Covid in the U.S in terms of Covid related deaths}

Table 1 reports cumulative Covid related deaths in the U.S. by age and in total, as reported by the Center for Disease Control, through September 11, 2021. These statistics indicate that Covid has indeed been a very serious disease. Since the first reported Covid death, 658,754 Covid related deaths have been reported, representing $12 \%$ of the $5,587,895$ total deaths reported over the same time period. In 2020 , Covid was the number three killer in the U.S., just behind heart disease and cancer.

The data in Table 1 also clearly indicate the Covid threat to life increases with age. About $55 \%$ of Covid deaths have occurred among people age 75 or older, which implies the median age of someone dying with Covid is over age 75. More than $91 \%$ of those dying with Covid have been 55 or older. Only about 7 in 10,000 Covid related deaths occur among those under age 18.

Table 2 presents the top three killers by age in 2019, before Covid hit. Note that preventable injury is the most common killer for those ages 1-44. Poison, falls, and motor vehicle accidents are the three most common preventable injury killers, comprising 83 percent of all preventable deaths (National Safety Council 2021.) There were 62,204 preventable injury deaths reported in 2019 for those under age 45, and from Table 1 we find there have been 21,678 Covid deaths reported from January 2020 to September 11, 2021 for the same age group. Thus, someone under age 45 is more than 3 times more likely to die from a preventable injury than from Covid. There were 14,547 suicide deaths among those aged 10-34 in 2019, and there were 7201 Covid deaths reported for those aged 5-34 over the longer January 2020 to September 11, 2021 period. Thus, someone aged 10-34 is more than twice as likely to die from suicide as from Covid. 
Table 2 Leading causes of death by age group 2019

\begin{tabular}{|c|c|c|c|c|}
\hline Age group & Rank & Cause of death & Deaths & $\begin{array}{l}\text { Deaths per } \\
100,000 \text { popula- } \\
\text { tion }\end{array}$ \\
\hline Less than 1 year & 1 & Congenital anomalies & 4301 & 113.7 \\
\hline Less than 1 year & 2 & Short gestation, low birth weight & 3445 & 91.1 \\
\hline Less than 1 year & 3 & Preventable injury & 1266 & 33.5 \\
\hline $1-4$ years & 1 & Preventable injury & 1149 & 28.4 \\
\hline $1-4$ years & 2 & Congenital anomalies & 416 & 10.3 \\
\hline $1-4$ years & 3 & Cancer & 285 & 7.0 \\
\hline $5-9$ years & 1 & Preventable injury & 714 & 17.6 \\
\hline $5-9$ years & 2 & Cancer & 371 & 9.1 \\
\hline $5-9$ years & 3 & Congenital anomalies & 192 & 4.7 \\
\hline $10-14$ years & 1 & Preventable injury & 778 & 18.7 \\
\hline 10-14 years & 2 & Suicide & 534 & 12.8 \\
\hline $10-14$ years & 3 & Cancer & 404 & 9.7 \\
\hline $15-24$ years & 1 & Preventable injury & 11,755 & 264.5 \\
\hline $15-24$ years & 2 & Suicide & 5954 & 134.0 \\
\hline $15-24$ years & 3 & Homicide & 4774 & 107.4 \\
\hline $25-34$ years & 1 & Preventable injury & 24,516 & 549.7 \\
\hline $25-34$ years & 2 & Suicide & 8059 & 180.7 \\
\hline $25-34$ years & 3 & Homicide & 5341 & 119.7 \\
\hline 35-44 years & 1 & Preventable injury & 24,070 & 606.7 \\
\hline 35-44 years & 2 & Cancer & 10,695 & 269.6 \\
\hline $35-44$ years & 3 & Heart disease & 10,499 & 264.6 \\
\hline $45-54$ years & 1 & Cancer & 35,587 & 826.5 \\
\hline $45-54$ years & 2 & Heart disease & 31,138 & 723.2 \\
\hline 45-54 years & 3 & Preventable injury & 23,359 & 542.5 \\
\hline 55-64 years & 1 & Cancer & 111,765 & 2829.1 \\
\hline $55-64$ years & 2 & Heart disease & 80,837 & 2046.2 \\
\hline 55-64 years & 3 & Preventable injury & 24,892 & 630.1 \\
\hline $65-74$ years & 1 & Cancer & 171,062 & 7492.3 \\
\hline $65-74$ years & 2 & Heart disease & 122,421 & 5361.9 \\
\hline $65-74$ years & 3 & Chronic lower respiratory diseases & 39,238 & 1718.6 \\
\hline $75-84$ years & 1 & Cancer & 160,639 & $15,044.5$ \\
\hline $75-84$ years & 2 & Heart disease & 158,287 & $14,824.3$ \\
\hline $75-84$ years & 3 & Chronic lower respiratory diseases & 50,791 & 4756.8 \\
\hline $85+$ years & 1 & Heart disease & 250,875 & $250,069.8$ \\
\hline $85+$ years & 2 & Cancer & 103,761 & $103,428.0$ \\
\hline $85+$ years & 3 & Alzheimer's disease & 78,688 & $78,435.4$ \\
\hline All Ages & 1 & Heart disease & 659,041 & 200.8 \\
\hline All Ages & 2 & Cancer & 599,601 & 182.7 \\
\hline All Ages & 3 & Preventable injury & 173,040 & 52.7 \\
\hline
\end{tabular}

https://injuryfacts.nsc.org/all-injuries/deaths-by-demographics/all-leading-causes-of-death/data-details Retrieved September 19, 2021 
Summarizing what we can learn from the data just presented:

(1) Covid is a very serious new health threat;

(2) The seriousness of the Covid health threat increases with age, so that Covid is a much more serious health threat to the elderly than to the young; and

(3) For every age group, there remains a more serious threat to heath than Covid.

\section{Evaluating reactions to Covid}

Given the data just presented, it is understandable that the primary goal of actions taken to reduce Covid is to reduce the loss of life. Consequently, economists have rightly sought to value the benefit of these actions. For decades, economists have used the value of a statistical life (VSL) to value the loss of life from various causes. Viscusi (2021) notes that his previous work puts the VSL at $\$ 11$ million, but he indicates a VSL of $\$ 5.2$ million is what he obtains if he adjusts for the fact that those dying from Covid are older.

Consistent with Viscusi's results, Robinson et al. (2021) obtain an age adjusted VSL estimate of $\$ 4.73$ million and an unadjusted estimate of $\$ 10.63$ million. Robinson et al. note the obvious fact that the measured net benefit to any action that reduces Covid deaths will be sensitive to the VSL number used. Surveying previous highly cited studies, Robinson et al. find that most researchers who show positive net benefits to lockdowns and other policy actions questionably apply the unadjusted VSL estimate. In doing so, those scholars roughly double the value associated with saving a life through a policy action.

Another key factor in the cost-benefit analysis is the infection fatality rate (IFR), the likelihood you will die from Covid if you get it. To illustrate its impact, Hall et al. (2020) estimate the maximum amount of consumption a person should be willing to give up to avoid dying from Covid. Using a $0.81 \%$ IFR coming from the Imperial College London study, they estimate you might give up $70 \%$ of a year's consumption to avoid a Covid death. Recognizing this high willingness to sacrifice might be resulting from a high and controversial IFR, Hall et al. also use a relatively low IFR of $0.44 \%$, a number obtained by factoring in the likely number of asymptomatic cases. Their consumption estimate is not only proportionate to the IFR, but also it is proportionate to the VSL assumed, and Hall et al. assume the VSL of about $\$ 10$ million. Adjusting the IFR to $0.44 \%$ reduces the consumption estimate to $38 \%$, and reducing the VSL to the age adjusted level further reduces the consumption estimate to less than $20 \%$. These different estimates illustrate how the estimated benefits of actions to reduce Covid deaths are highly dependent upon both the VSL and IFR.

Even more challenging is estimating the degree to which actions will reduce Covid deaths. Prior to the development of vaccines, policy makers pursued a variety of non-pharmaceutical interventions (NPIs). Such interventions save lives primarily by reducing the rate and extent to which the virus spreads, reducing deaths, relieving the pressure on medical resources, and giving more time for vaccines and treatments to be developed. How does a scholar estimate the impacts of an NPI or multiple NPIs? 
One approach is to identify "natural experiments," where one governmental jurisdiction adopts an NPI that another does not. For example, Juranek and Zoutman (2021) use the fact that Denmark and Norway implemented "lockdowns" (i.e., school closing, workplace closing, cancelation of public events, gathering restrictions, and travel restrictions) on specific dates whereas Sweden did not. Their estimated model indicates not locking down increases the number of hospitalizations 2-4 times and the number of deaths 5-11 times. Broughel and Kotrous (2021) use the fact that 38 states implemented "stay at home" orders for their residence at some point in April 2020, but the others did not. They find the loss of production from the stay at home orders they examined, enforced for periods ranging from 42 to 65 days, provided about twice the economic benefit (lives saved, hospital costs, and more) than was paid in terms of lost production.

A relatively novel natural experiment approach has been to use mobility reports obtained from smart phones to examine how government restrictions reduced mobility. Chernozhukov et al. (2021) use this approach to estimate the impact of government restrictions separate and distinct from the voluntary restrictions people would take in response to the Covid threat. They find that variations in government restrictions across U.S. states in the form of K-12 school closures, restaurants closures, movie theater closures, and non-essential business closures explain more than $50 \%$ of the reduction in observed movements. They find masking, business closures, and stay at home orders all had significant impacts on the spread of the virus. Using their estimated model, they indicate universal masking at the beginning of the pandemic in early March, 2020 would have saved 34 thousand lives by June of 2020; not closing businesses would have increased cases and deaths by $40 \%$, and not issuing stay at home orders would have increased cases and deaths by $37 \%$.

Gupta et al. (2020) examine mobility in great depth, using four different mobility data sources. They carefully examine the timing of different government actions, and rather convincingly show that decreases in mobility, a proxy for an increase in social distancing, occurred voluntarily in response to understanding the seriousness of the virus, though government mandates added to the response. In particular, they found emergency declarations of states and national government in early to mid March, which occurred before more significant mandated business closures and stay at home orders, accounted for more than half the decreases in mobility. Moreover, states that did not issue stay at home orders nonetheless experienced decreases in mobility nearly as great as states issuing stay at home orders.

Goolsbee and Syverson (2020) obtain similar findings using cell phone data records to track customer visits to businesses. Specifically, they find that the rise of Covid reduces customer visits by 60 percent, but only 7 percentage points of this total are due to legal restrictions. Individual choices, presumably in response to fears of infection, account for most of the decrease. Goolsbee and Syverson, like Gupta et al., find that lifting restrictions increases customer visits some but the increases were modest. That is, the examination of mobility data indicates people significantly respond to the Covid threat without legal requirements to do so.

Relative to most scholars, Frijters et al. (2021) have judged government policy responses to be over reactions. Indeed, to emphasize the degree of over-reaction, they title their book The Great Covid Panic. They contend studies finding net 
benefits tend to assume infection fatality rates and values for statistical life that are too high. Even more significantly, they note the typical study leaves out categories of costs for NPIs (especially lockdowns) that are large, including the additions to government debt, ${ }^{2}$ non-Covid health problems created by the NPIs, reductions in life satisfaction, and education losses in children. As a specific example of a cost left out, they note that the UK lockdown included a provision that deemed in-vitro fertilizations non-essential, yet about $3 \%$ of UK births arise from in-vitro fertilization. Whereas Frijters et al. estimate the average Covid death takes away about 3 years of expected life, the estimated lifespan the average in-vitro child not born is 80 years. That is, in expected years of life saved, giving up one in-vitro child must reduce Covid deaths by about 28 in order to pencil, yet the typical study would not even consider in-vitro children foregone as a cost. Overall, Frijters et al. estimate a UK style lockdown generates costs that are 3 to 4 times the benefits.

From an economic perspective, government reasonably takes actions to fight Covid to address the negative externality problem that arises when a person with Covid affects another, but Frijters et al. (2021) provide evidence that the Covid responses of more developed countries have generated negative externalities that especially impact less developed countries. They report that Covid responses have disrupted vaccination programs for measles, diphtheria, cholera, and polio in 70 countries and estimate the responses have moved an additional 100 million people into extreme poverty (living on less than $\$ 2$ per day). They predict these reduced vaccinations and increased poverty will cost millions of lives in less developed countries, and they contend aid spent on Covid for less developed countries would save more lives if it were spent on improving water quality, providing vaccinations for diseases more serious than Covid, basic medical care, and other more pressing concerns.

Chaudhury (2021) also presents much evidence that policy makers have over reacted to the Covid threat. Like Frijters et al., Chaudhuri contends those finding net benefits to lock downs fail to recognize significant direct costs and opportunity costs. However, Chaudhury also identifies many behavioral factors that caused over reaction. He contends our system 1, gut feeling, heuristic thinking leads to excessively focus on Covid deaths alone as a measure of failure or success, rather than more fruitfully considering Covid deaths in the context of other possible ways to die. He notes that policy makers and journalists tend to negatively frame the infection fatality rate of 0.07 as 7 of 1000 will die rather than positively framing the situation as 993 of 1000 will live. This type of this negative frame is well-known to motivate more concern. Chaudhury works in New Zealand, which many have recognized as exemplary in its efforts to address Covid. However, Chaudhury contends

\footnotetext{
${ }^{2}$ While deficits have been the norm for the U.S. national government since the mid 1970 s, Covid related spending in 2020 increased the deficit dramatically. National income and product account data available at https://apps.bea.gov/iTable/iTable.cfm?reqid=19\&step=2\#reqid=19\&step=2\&isuri=1\&1921=survey indicates the U.S. federal deficit was $\$ 1.5$ trillion larger in 2020 than in 2019. All governments (federal, state, and local) combined ran deficits equal to $14.8 \%$ of GNP in 2020, the highest percentage ever. By way of comparison, all governments ran deficits equal to $12.6 \%$ and $13.5 \%$ of GNP when WWII spending peaked in 1944 and 1945.
} 
the accolades are not deserved because New Zealand's island status accounts for much of its success, and comparisons with Japan and other island nations indicate New Zealand could have reduced the costs it paid significantly by avoiding mass lockdowns and with focus on limiting larger indoor gatherings and actions to protect the elderly.

\section{How can we do better?}

It is rational to respond to a new health threat like Covid, individually and collectively, but the behavioral economic ideas presented above indicate we will tend to over-react. Recognizing the different behavioral factors causing bias toward overreaction will help us develop appropriate checks on our decision behaviors. Explicitly recognizing our bias toward over-reacting should also motivate and discipline us toward applying standard economic decision tools.

Frijters et al. (2021) and Chaudhury (2021) each note they were motivated to write a book about Covid policy making because policy makers, and even wellknown economists, were not sufficiently applying basic economic concepts (e.g., thinking at the margin, the law of diminishing returns, and opportunity cost). How to best address a new health or safety threat is a relatively standard economic problem. To do as well as possible, standard decision making principles indicate you should (1) apply resources (i.e., time and money) to obtain improvement, (2) take the most useful actions first because resources are limited, (3) recognize there will be diminishing returns to your efforts, and (4) stop applying additional resources when those resources are better applied to another concern. Yet, as Chaudhury (2021, p. 15) notes, the goal of many policy makers has seemed to be to "minimize the loss of lives from Covid-19 regardless of cost."

Addressing Covid is more complex because decision makers tend to generate externalities as they respond to the new health threat. Coase (1960, p.44) anticipated that policy makers might not improve matters much as they address externalities because they may not "bear in mind that a change in the existing system which will lead to an improvement in some decisions may well lead to a worsening of others." What worsening might policy makers especially not consider? There is much evidence that "richer is healthier and safer," and regulations aimed at reducing a health or safety threat like Covid will often hinder economic growth, thereby reducing the net improvements to health and safety (Wildavsky 1981). Viscusi (2021) estimates losing $\$ 100$ million of production leads to the loss of one statistical life. Regulatory restrictions also disproportionately worsen the lives of those who are poorer (Thomas 2019). Policy makers probably do not often consider that poorer people adapt (e.g. by buying cheaper food) to the costs (e.g., higher prices and lost income) of new regulations in ways that tend to increase their health risks.

We will more likely apply basic economic decision concepts as we should, and more likely bear in mind the costs of actions we take, if we recognize there are behavioral forces that tend to lead us astray. We should guard against emotional responses, recognizing that a new risk especially invokes an emotional response, which Loewenstein (2000, p. 431) warns may be "destructive in the long run." 
We should base "public policy [and our own individual choices] on the best scientific assessments of risk severity" (Loewenstein et al. 2000, p. 281). This will reduce the ambiguity that typically accompanies a new risk, which will reduce the degree to which ambiguity magnifies our perception of the risk and causes us to over-react. We should more carefully identify the opportunity costs of different actions, which will reduce the degree to which the status quo, loss aversion, and endowment effect bias us toward addressing the new threat.

Explicitly considering the heterogeneity of the population will also guard against over-reaction. Given the varying impacts of Covid by age, it is not surprising that people 65 years of age and older have said, by a 6 to 1 margin, that it is more important for government to address the spread of the virus than worry about the impacts on the economy; younger people are not nearly as concerned (Morning Consult 2020). With less incentive to pay costs to reduce their health risk, the young are more likely to produce and impose negative external costs on the old. It is reasonable that government act to reduce these externalities, but how far should government go? Clearly, the answer must depend upon how much weight we put on the interests of the elderly versus the young.

Another check on over-reaction would be to recognize explicitly that government intervention will yield diminishing returns. Coase (1960, p. 18) warned that we should not "suppose that the restrictive ... regulations, made by a fallible administration subject to political pressures and operating without any competitive check, will necessarily" be efficient. To illustrate, retired people (like my wife's mom), whose financial lives were unaffected by Covid, nonetheless received the $\$ 1200$ "relief" payment authorized under the \$2.2 trillion CARES Act. Such inefficiency naturally arises from the difficulty of tailoring a national program to a heterogeneous population. Heterogeneity also implies government intervention will tend to generate externalities even as government seeks to ameliorate them. This is because some will disproportionately benefit while others will disproportionately pay the costs. The inefficiencies and externalities will increase as government seeks to do more. Recognizing the diminishing returns caused by these and other factors will mitigate the over-reaction tendency.

At what level should government respond? When an individual, a business, a group, or a lower level government reacts mildly and incurs fewer costs to address a new threat like Covid, they are receiving positive externalities (mainly a lower risk of being infected) from and imposing negative externalities (mainly a higher risk of being infected) on those reacting strongly and incurring higher costs. This is the primary factor rationalizing higher-level government action. However, if risks and interests vary, it is difficult for a higher-level government to construct a policy that aligns with the varying conditions. Moreover, when we do not allow lower level governments or non-government entities to vary their responses, we do not put the laboratory of democracy to work, so we cannot fruitfully adapt based upon what we learn by observing the varying results of the varying responses. A higher level of government over-reacts when it insufficiently considers the usefulness of allowing different lower level reactions. Moreover, everyone experiences any over-reaction made by the highest level of government. 
Elinor Ostrom found that "effective tools of governance" do not necessarily reside "in the formal structure of government," but often instead reside "in the informal, and sometimes even tacit, rules that communities live by" (Boettke 2010, p. 283). In the private sector, the potential for losses mitigates the risk taking that the pursuit of profit encourages, and firms develop effective rules of operation to balance the two. How might state and local governments, non-profits, and less formal communities develop effective rules, including rules for balancing competing risks? Ostrom's work indicates effective rules develop as governing entities compete for residents and participants. Effective rules capture the benefits of cooperation, but they also mitigate the costs of conflict. A higher level of government over-reacts when it does not consider the reduction in effective governance its action may cause by reducing competition at lower levels.

\section{Conclusion}

The new Covid threat has been and is still very serious, rationally deserving a strong response, individually and collectively. Yet, the behavioral factors identified in this paper indicate individuals, businesses, other non-governmental entities, and governments will tend to over-react, not only to Covid but also to any new, low probability threat to health.

Given the strong incentives non-government decision makers have to act, the primary reason for government to act is to address externalities. Because Covid disproportionately threatens the elderly and those less healthy, externalities primarily arise because the young and those who are healthier have less incentive to address the threat. Prior to the development of the vaccines, you could rationalize government intervention actions to mitigate the negative externalities younger and healthier people would tend to emit and impose upon older and less healthy people. Moreover, you could rationalize strong government action if you place a high value on the health and lives of older and less healthy people compared to the value you place on the foregone opportunities of the young and healthier people. However, with effective vaccines now readily available, the externality rationale for strong government intervention is much weaker.

Absent a significant externality, government intervention amounts to government over-ruling the risk balancing and cost-benefit judgments of individuals, businesses, and other non-government entities. Some might argue government should rescue people from their own bad choices, but most would not, even when the bad choices impose some costs on others. There are many decisions a person can make that most would say are bad for individual health or well-being. Smoking and overeating especially come to mind. They increase the health insurance premiums we all pay, and those engaging in these activities disproportionately take up hospital beds. Governments often discourage such unhealthy behaviors, by taxing them or by taking other actions to nudge people toward healthier choices. Yet, most societies value individual freedom enough that they still allow people to make choices for themselves that a majority considers bad. The fact that many governments are still imposing significant restrictions, after the ready availability of vaccines has substantially 
reduced externalities, is further evidence that the behavioral factors identified in this paper are still prompting an over-reaction to the Covid threat.

Meenagh and Minford (2021) present one of the few models of coronavirus transmission that recognizes individuals, government, and the virus will all adapt over time. Fitting their model to the data, they find more costly government restrictions largely displace less costly voluntary restrictions individuals would otherwise place upon themselves in response to the virus. They also find government jurisdictions taking stronger government actions had less significant virus first waves but stronger second waves, concluding this is most likely because the virus has an evolutionary motivation to adapt to find the hosts it did not find earlier. Their second wave estimations also indicate more decentralized and targeted government restrictions will outperform more centralized restrictions long term.

Because the Corona virus adapts, it is not likely that we will eradicate it any time soon. It is more likely that we will have to adapt to it in the same way we have adapted to what have been the more common flu viruses. We will adapt more effectively in the future than in the past, not only because we will learn from our experiences but also because time and experience will ameliorate the impact of the behavioral factors identified in this paper that prompt us to over-react. The hope of this paper is that we do not have to wait for time and experience to have their impact. Rather, we can adapt more effectively sooner by recognizing the behavioral factors biasing us toward over-reaction.

\section{References}

Allais M (1953) Le comportement de l'homme rationnel devant le risque: Critique des postulats et axiomes de I'Ecole Americaine. Econometrica 21:503-546

Boettke P (2010) Is the only form of 'reasonable regulation' self regulation?: Lessons from Lin Ostrom on regulating the commons and cultivating citizens. Public Choice 143:283-291

Broughel J, Kotrous M (2021) The benefits of coronavirus suppression: a cost-benefit analysis of the response to the first wave of COVID-19 in the United States. PLoS ONE. https://doi.org/10.1371/ journal.pone.0252729,1-20

Carrigan C, Coglianese C (2015) The Oxford handbook of classics in public policy and administration. In: Lodge M, Page EC, Balla SJ (eds) Chapter 20: George j. Stigler. The theory of economic regulation. OUP, pp 287-299

Chateauneuf A, Eichberger J, Grant S (2007) Choice under uncertainty with the best and worst in mind: Neo-additive capacities. J Econ Theory 137:538-567

Chaudhuri A (2021) Nudged into lockdown? Behavioural economics, uncertainty and Covid-19. Edward Elgar, London

Chernozhukov V, Kasahara H, Schrimpf P (2021) Causal impact of masks, policies, behavior on early covid-19 pandemic in the U.S. J Econom 220:23-62

Coase R (1960) The problem of social cost. J Law Econ 3:1-44

Doring T, Schnellenbach J (2011) A tale of two federalisms: Germany, the United States and the ubiquity of centralization. Constit Polit Econ 22:83-102

Florio M, Colautti S (2005) A logistic growth theory of public expenditures: a study of five countries over 100 years. Public Choice 122:355-393

Frijters P, Foster G, Baker M (2021) The great Covid panic: what happened, why, and what to do next. Brownstone Institute, Austin

Gilboa I, Schmeidler D (1989) Maxmin expected utility with non-unique prior. J Math Econ 18(2):141-153 
Goolsbee A, Syverson C (2020) Fear, lockdown, and diversion: comparing the drivers of the pandemic economic decline 2020. National Bureau of Economic Research. Working Paper No. 27432. http:// www.nber.org/papers/w27432

Gupta S, Simon K, Wing C (2020) Mandated and voluntary social distancing during the COVID-19 epidemic. Brookings Papers on Economic Activity, Summer, pp 269-315

Hall RE, Jones CI, Kleneow PJ (2020) Trading off consumption and COVID-19 deaths. Q Rev Federal Reserve Bank Minneapolis 42(1):1-13

Higgs R (2010) Cumulating policy consequences, frightened overreactions, and the current surge of government's size, scope, and power. Harvard J Law Public Policy 33(2):531-556

Juranek S, Zoutman FT (2021) The effect of non-pharmaceutical interventions on the demand for health care and on mortality: evidence from COVID-19 in Scandinavia. J Popul Econ 2021(34):1299-1320

Kahneman D, Knetsch JL, Thaler RH (1990) Experimental tests of the endowment effect and the Coase theorem. J Polit Econ 98(6):1325-1348

Kahneman D, Tversky A (1979) Prospect theory: an analysis of decision under risk. Econometrica 47(2):263-292

Loewenstein G (2000) Emotions in economic theory and economic behavior. Am Econ Rev 90(2):426-432

Loewenstein GF, Weber EU, Hsee CK, Welch N (2001) Risk as feelings. Psychol Bull 127(2):267-286

Meenagh D, Minford P (2021) A structural model of coronavirus behaviour for testing on data behaviour. Appl Econ 53(30):3515-3534. https://doi.org/10.1080/00036846.2021.1883531

Morning Consult (2020) https://morningconsult.com/form/older-americans-sour-on-trumps-handling-ofthe-outbreak/ Accessed 17 May 2020

National Safety Council (2021) https://injuryfacts.nsc.org/allinjuries/deaths-by-demographics/all-leadi ng-causes-of-death/data-details/ Accessed 19 Sept 19

Peltzman S (1976) Toward a more general theory of regulation. J Law Econ 19:211-222

Robinson LA, Sullivan R, Shogren J (2021) Do the benefits of COVID-19 policies exceed the costs? Exploring uncertainties in the Age-VSL relationship. Risk Anal 41(5):761-770

Samuelson W, Zeckhauser R (1988) Status quo bias in decision-making. J Risk Uncertain 1:7-59

Stigler GJ (1971) The theory of regulation. Bell J Econ Manag Sci 2:1-21

Sunstein C, Zeckhauser R (2011) Overreaction to fearsome risks. Environ Resour Econ 48:435-449

Thomas DW (2019) Regressive effects of regulation. Public Choice 180:1-10

Viscusi K (2021) Economic lessons for Covid-19 pandemic policies. South Econ J 87:1064-1089

Wildavsky A (1981) Richer is safer. Financ Anal J 37(2):19-22

Wuthisatian R, Mahmoudi M, Pingle M (2022) Taking chances or not: Ambiguity can explain a lot (Unpublished Manuscript)

Publisher's Note Springer Nature remains neutral with regard to jurisdictional claims in published maps and institutional affiliations. 